$\S=-1$

\title{
Influence of Boron Carbide Addition on Performance and Neutron Shielding Ability of Cement Mortar Mix
}

\author{
Satish A J $\mathbf{J}^{\mathrm{a}}$, Aravind $\mathbf{P} \mathbf{N}^{\mathrm{b}}$, Hakesh $\mathbf{P} \mathbf{V}^{\mathrm{c}}$, Vignesh $\mathbf{V}^{\mathrm{d}}$, Dr Mini $\mathbf{K} \mathbf{M}^{\mathrm{e} *}$, \\ ${ }^{a, b, c, d}$ Undergraduate Students \\ e Professor \& Chairperson \\ Department of Civil Engineering, Amrita School of Engineering - Coimbatore, Amrita Vishwa Vidyapeetham, Amrita University, \\ Tamil Nadu, India - 641112. \\ *Corresponding authorE-mail: k_mini@cb.amrita.edu
}

\begin{abstract}
Renewable source of energy is the best form of consumable energy that can be harnessed from the earth's available resources in a sustainable manner. Nuclear energy obtained from nuclear fission reactions from the nuclear reactors is an example of such kind of energy, but deeply requires caution in the handling of operations. Leakage of fast moving high energy neutrons creates harm to both the environment and mankind and hence should be shielded from all available means. One such effort to shield this high energy radiation is by using boron carbide infused cement mortar that can be used for plastering and other similar applications in the construction of nuclear reactors. The strength and performance based characteristics of such type of mortar are studied and improved by adding super-plasticiser and pozzolanic materials like microsilica and metakaolin. Also durability studies like alkalinity, water absorption etc are done to analyse the lifetime of the design mix. EDS and SEM analysis were also performed extensively to study the microstructure of the casted specimen and to analyse the elemental composition cum distribution (by EDS mapping) for the calculation of the neutron attenuation of the specimen mix. Based on these an optimum combination is arrived at for practical applications that has a desirable strength, performance, durability and neutron shielding property.
\end{abstract}

Keywords: Boron Carbide; Compressive Strength; EDS; Masterglenium SKY 8233; Metakaolin; Micro Silica; mortar; Neutron attenuation; removal cross section; SEM.

\section{Introduction}

Neutron radiation is a type of ionisation radiation that is easily penetrable to objects like human body, walls of structure etc and can cause serious effects to both environment and humanity. This high energy radiation in the field of nuclear research industry is generally shielded using thick lead blocks and heavy water.

Concrete with water content of $7 \%$ is more than enough to slow down the neutrons having intermediate energy, this shows that water in itself is one of the most cheap and efficient mode for shielding the neutrons, but the incoming neutrons after colliding with water molecules may first get slowed down and act as an initiator for the emission of secondary gamma radiation ${ }^{[1]}$. It has been experimentally verified by many that high density concretes have considerable neutron shielding property and thus can be simultaneously employed for this cause ${ }^{[8]}$. Concrete containing elements like hydrogen, iron can make the concrete dense and thus can effectively shield fast moving neutrons ${ }^{[20]}$.

Boron comes fifth in the periodic table and boron carbide is denoted as $\mathrm{B}_{4} \mathrm{C}$. It is the hardest known material after diamond and cubic boron nitride. These are crystalline in nature and insoluble in water. Boron and its compounds have their application in nuclear industry ${ }^{[7]}$ because of high neutron absorption cross section ${ }^{[15]}$. Experimental investigations on mechanical, physical and structural properties of concrete containing boron carbide are conducted. It showed that when boron carbide is used in concrete as an absorbing material for neutrons in nuclear reactors, the concrete density decreases as the percentage of boron carbide increases and also a higher content of boron carbide in concrete resulted in reduction of strength ${ }^{[17]}$. Contrastingly the results also show that as and when thickness of the sample and percentage of boron carbide increase, the neutron attenuation values also increase ${ }^{[18]}$. The isotope of boron, ${ }^{10} \mathrm{~B}$ has a capture cross section that is high and can easily capture the thermal neutrons ${ }^{[20]}$. Similar to boron carbide, ferro-boron also possesses radiation shielding characteristics, and therefore an optimum combination of both is thus definitely enhancing the shielding effect ${ }^{[21]}$. Many naturally available ore resources like colemanite (abundantly found in turkey) can also be added to concrete for same reasons ${ }^{[20]}$.

The neutron attenuating property of a material can be experimentally determined by testing in the sophisticated nuclear radiation setup in radioactive research centers ${ }^{[15]}$. These observations can also be mathematically calculated using some verified hand calculation methods with the help of standard available microscopic cross section value database for element ${ }^{[19]}$, compound and other materials or by software based calculation analysis like Monte Carlo analysis etc., and hence determining the comprehensive macroscopic cross section values of the sample ${ }^{[11]}$.

The present paper reports the work done using $\mathrm{B}_{4} \mathrm{C}$ in cement mortar to enhance its neutron shielding capacity which is analysed by removal cross section study. It also addresses the changes in fresh and hardened properties of cement mortar due to addition of $\mathrm{B}_{4} \mathrm{C}$. As the previous researchers reported a reduction in strength due to addition of $\mathrm{B}_{4} \mathrm{C}$ in concrete, a study using admixture like microsilica and metakaolin is also carried out. The objective of the 
project is to find out the change in compressive strength, workability along with durability and neutron shielding ability of the mortar mixes taken for consideration. The shielding capacity of $\mathrm{B}_{4} \mathrm{C}$ is inferred by removal cross section study. Durability tests like water absorption, sorptivity test, alkalinity tests on all specimens were performed.

\section{Methodology}

1:2 mortar mix is taken as the control specimen. Boron carbide is added in different quantities as specified in Table 2 and characteristics like compressive strength, alkalinity and workability were noted. Based on the results the best $\mathrm{B}_{4} \mathrm{C}$ mix is taken and various proportions of metakaolin and microsilica are added to it and all parameters are evaluated. The best of all combination of mixes is suggested based on the performance and durability parameters.

\section{Material selection}

The present investigation focused on analysing the changes occurring in the neutron shielding ability, compressive strength, workability, durability of $1: 2$ (cement : sand) mortar mix when infused with varying amount of boron carbide (D50 size 15 micron) conforming to IS $15850: 2009$ having specific gravity 2.52. Fly-ash based Portland Pozzolana cement manufactured by Chettinad Cements Ltd., river sand passing through $1.18 \mathrm{~mm}$ IS Sieve with specific gravity of 2.57 and masterglenium sky 8233 manufactured by BASF Construction Chemicals was used.

\section{Mix design Selection}

The details of test specimen and quantity of materials for mixes are presented in Table 1 and Table 2 .

Table 1: Description of test specimen

\begin{tabular}{|c|c|}
\hline DESCRIPTION & $\begin{array}{l}\text { SPECIMEN } \\
\text { NAME }\end{array}$ \\
\hline 1:2 mortar mix (Control Mix) & $\mathrm{A}$ \\
\hline $\begin{array}{l}15 \% \text { cement weight of fine aggregate replaced by boron } \\
\text { carbide }\end{array}$ & B \\
\hline $\begin{array}{l}20 \% \text { cement weight of fine aggregate replaced by boron } \\
\text { carbide }\end{array}$ & $\mathrm{C}$ \\
\hline $\begin{array}{l}25 \% \text { cement weight of fine aggregate replaced by boron } \\
\text { carbide }\end{array}$ & $\mathrm{D}$ \\
\hline $\begin{array}{l}15 \% \text { cement weight of fine aggregate replaced by boron } \\
\text { carbide and 5\% of cement replaced by silica fumes }\end{array}$ & $\mathrm{E}$ \\
\hline $\begin{array}{l}15 \% \text { cement weight of fine aggregate replaced by boron } \\
\text { carbide and } 10 \% \text { of cement replaced by silica fumes }\end{array}$ & $\mathrm{F}$ \\
\hline $\begin{array}{l}15 \% \text { cement weight of fine aggregate replaced by boron } \\
\text { carbide and } 15 \% \text { of cement replaced by silica fumes }\end{array}$ & G \\
\hline $\begin{array}{l}15 \% \text { cement weight of fine aggregate replaced by boron } \\
\text { carbide and } 5 \% \text { of cement replaced by metakaolin }\end{array}$ & $\mathrm{H}$ \\
\hline $\begin{array}{l}15 \% \text { cement weight of fine aggregate replaced by boron } \\
\text { carbide and } 10 \% \text { of cement replaced by metakaolin }\end{array}$ & I \\
\hline $\begin{array}{l}15 \% \text { cement weight of fine aggregate replaced by boron } \\
\text { carbide and } 15 \% \text { of cement replaced by metakaolin }\end{array}$ & $\mathrm{J}$ \\
\hline
\end{tabular}

Therefore a total of 30 specimens ( 3 cubes in each combination) were prepared and tested.

Table 2: Quantity of materials for mixes

\begin{tabular}{|c|c|c|c|c|c|c|c|}
\hline 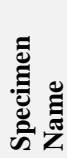 & 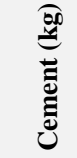 & 莺 & 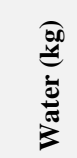 & 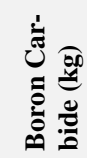 & 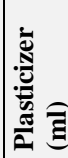 & 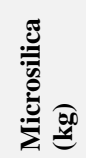 & 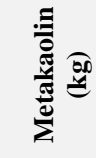 \\
\hline A & 0.275 & 0.550 & 0.137 & - & 2 & - & - \\
\hline B & 0.275 & 0.508 & 0.137 & 0.041 & 2 & - & - \\
\hline $\mathrm{C}$ & 0.275 & 0.495 & 0.137 & 0.054 & 2 & - & - \\
\hline D & 0.275 & 0.481 & 0.137 & 0.068 & 2 & - & - \\
\hline
\end{tabular}

\begin{tabular}{|l|l|l|l|l|l|l|l|}
\hline $\mathrm{E}$ & 0.253 & 0.508 & 0.137 & 0.041 & 2 & 0.011 & - \\
\hline $\mathrm{F}$ & 0.240 & 0.508 & 0.137 & 0.041 & 2 & 0.022 & - \\
\hline $\mathrm{G}$ & 0.227 & 0.508 & 0.137 & 0.041 & 2 & 0.033 & - \\
\hline $\mathrm{H}$ & 0.253 & 0.508 & 0.137 & 0.041 & 2 & - & 0.013 \\
\hline $\mathrm{I}$ & 0.240 & 0.508 & 0.137 & 0.041 & 2 & - & 0.027 \\
\hline $\mathrm{J}$ & 0.227 & 0.508 & 0.137 & 0.041 & 2 & - & 0.040 \\
\hline
\end{tabular}

\section{Experimental Investigations}

All specimens were made to a size of $70 \mathrm{~mm}$ size cubes and cured to a period of 28 days. Fresh state and hardened properties on all specimens were conducted. In addition to this, study on density, alkalinity, absorption and sorptivity tests were also carried out on all hardened specimen.

\section{Results and DISCUSSIONS}

\subsection{Compressive Strength}

\subsubsection{Replacement of Fine Aggregate with $\mathrm{B}_{4} \mathrm{C}$}

Figure 1 reports the compressive strength of test specimen A, B, C and $\mathrm{D}$ to get the optimum value of boron carbide in terms of strength. From Figure 1 it is observed that addition of $\mathrm{B}_{4} \mathrm{C}$ in place of fine aggregate shows improvement in strength. Cement mortar with $15 \%$ sand replacement with boron carbide was found to have the maximum compressive strength as it contains larger volume of fine aggregate than specimen $\mathrm{A}$ and lesser volume of $\mathrm{B}_{4} \mathrm{C}$ as compared to other specimen.

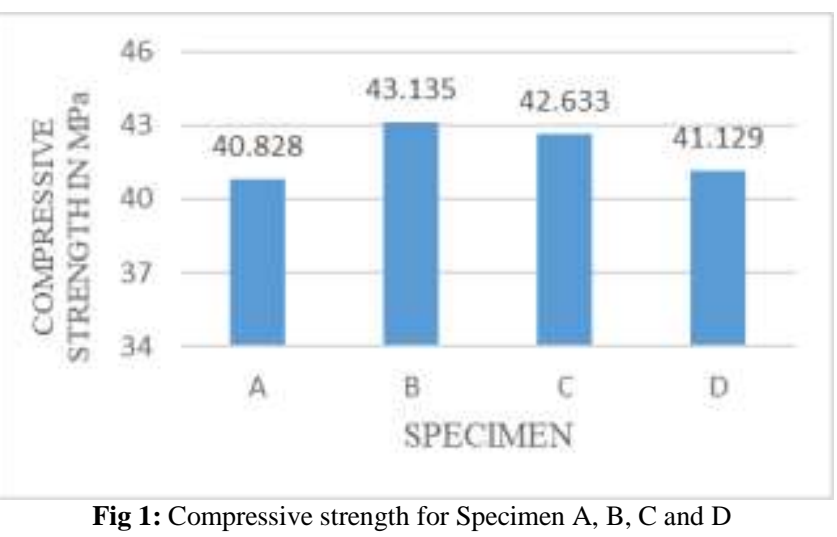

Figure 1 also shows that replacement of fine aggregate with $\mathrm{B}_{4} \mathrm{C}$ does not influence much on the strength property as a mere $5.35 \%$ improvement was achieved for $15 \%$ replacement.

Hence all the remaining specimens were casted with $15 \% \mathrm{~B}_{4} \mathrm{C}$ as fixed amount and by adding various proportions of micro silica and metakaolin as a replacement for cement to enhance its strength properties.

\subsubsection{Replacement of Cement with Pozzolanic Materials}

Calcium hydroxide (lime) accounts for up to a quarter of the total hydrated Portland cement, and lime does not contribute to the strength or durability. Pozzolans like microsilica and metakaolin that are used as a cement replacement reacts with lime to produce a cementitious gel which further hardens with time and thus leads to the formation of additional calcium silicate hydrate, which is responsible for strength characteristics of the specimen. The value of compressive strength of the specimen will also depend upon the individual strength of aggregates, amount of compaction and curing temperature. 


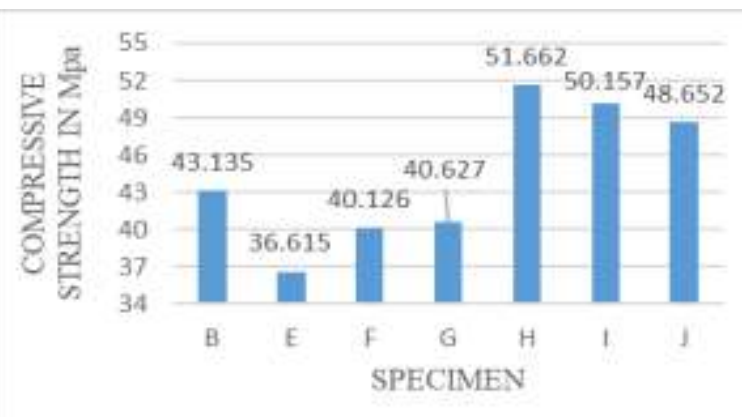

Fig 2: Compressive strength for Specimen B, E, F, G, H, I\& J

Figure 2 shows the graphical representation of values for compressive strength for specimen B with other pozzolanic added mortar specimen.

On addition of metakaolin, the compressive strength of the specimen increases on the whole compared to micro silica but there is a reduction in strength proportionally with increase in percentages of metakaolin. This shows that the formation of pozzolanic cementitious gel is more in metakaolin than micro silica.

As the percentage of boron carbide (as a fine aggregate) in the specimen increases, the strength of the specimen is found to decrease $^{[17]}$. The use of pozzolans as cement replacement was found to be efficient on strength and cost basis as the value of specimen E,F,G,H,I and $\mathbf{J}$ either closely resembles or have a higher value when compared to the control specimen A in most of the cases.

The $15 \% \mathrm{~B}_{4} \mathrm{C}$ containing mortar cube with $5 \%$ metakaolin as cement replacement " $\mathrm{H}$ " was found to possess maximum compressive strength.

\subsection{Flowability}

The flow table test is done to find out the flowability of the fresh mortar which indicates the workability of the mix. Glenium superplasticiser of $2 \mathrm{ml}$ was added in all specimen mixes to improve the workability.

\subsubsection{Replacement of Fine Aggregate with $\mathrm{B}_{4} \mathrm{C}$}

As the figure 3 shows the flowability values for the specimen $\mathrm{B}, \mathrm{C}$, $\mathrm{D}$ and $\mathrm{A}$, it is observed that as the percentage of $\mathrm{B}_{4} \mathrm{C}$ in the mix increases, the mortar becomes more stiff and non-workable, therefore the specimen $\mathrm{B}$ with maximum flowability is chosen to be best among $\mathrm{B}, \mathrm{C}, \mathrm{D}$ and $\mathrm{A}$. The increase in workability from A to $\mathrm{B}$ and then reduction in values further shows that the addition of specific amount of boron carbide to the mix results into a product with higher workability. The reason behind such an observation might be due to the very fine particle size of boron carbide that possesses a different physical property than its conventional nature. Further the physio-chemical reaction between fine boron carbide particles and the rest of the matrix in specimen B makes the entire product highly workable. Thus it can be inferred that the fineness and amount of boron carbide in the mortar plays a crucial role in the workability of the resultant mix.

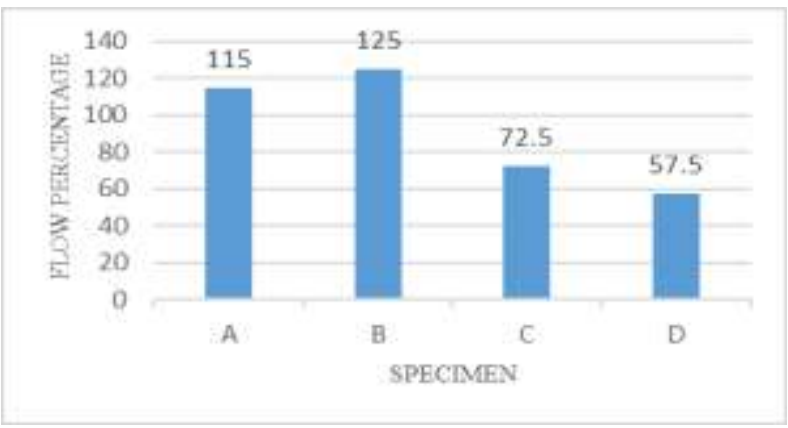

Fig 3: Flow percentage for specimen A, B, C and D

\subsubsection{Replacement of Cement with pozzolanic materials}

Flowability tests for specimen containing pozzolanic materials like microsilica and metakaolin are also conducted and the observations are represented in figure 4 .

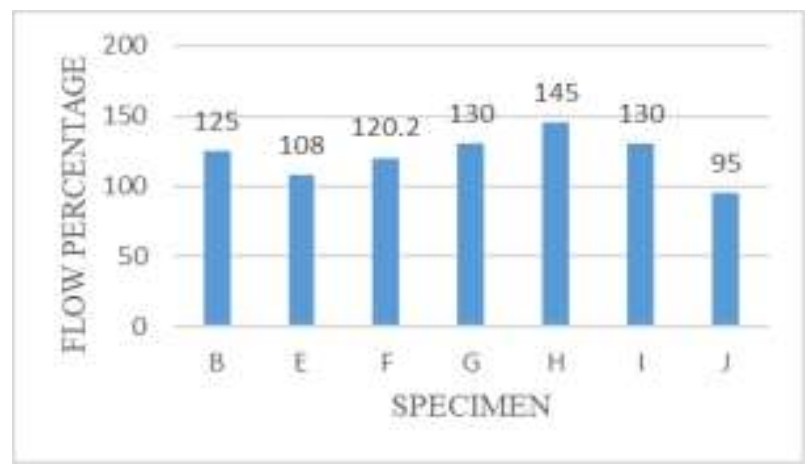

Fig 4: Flow percentage for specimen B, E, F, G, H, I and J

The increasing flow percentage in specimen $\mathrm{E}, \mathrm{F}$ and $\mathrm{G}$ denotes that the net surface area of the components of the mortar mix has increased due to addition of microsilica. This shows that on adding microsilica, the product formed has a larger surface area which is opposite in case of specimen $\mathrm{H}$, I and $\mathrm{J}$ where cement was replaced with metakaolin. Thus it can be inferred that to improve the workability of a mortar mix metakaolin is the best pozzolana.

A mortar which possesses maximum flowability percentage without any segregation is chosen to be best for all practical purposes. Therefore specimen $\mathrm{H}$ possessing highest flowability among all others is chosen and thus suggested.

\subsection{Density}

The ratio of weight to volume of the motor cube gives the bulk density of that specimen. The density of all specimens is presented in figure 5 .

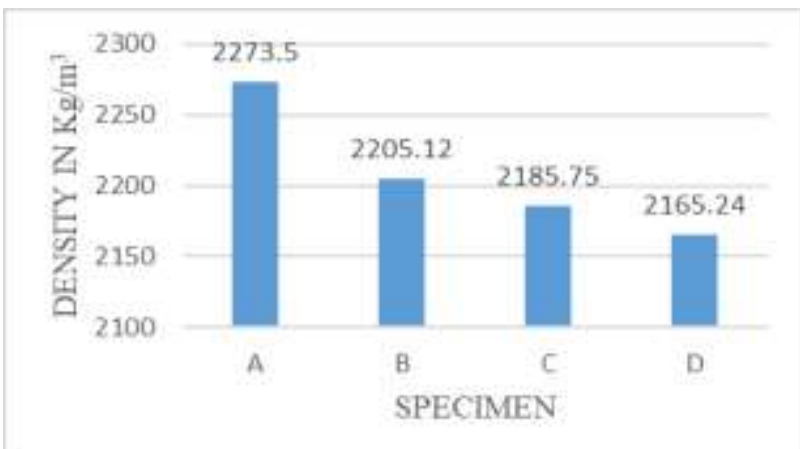

Fig 5: Density for specimen A, B, C and D

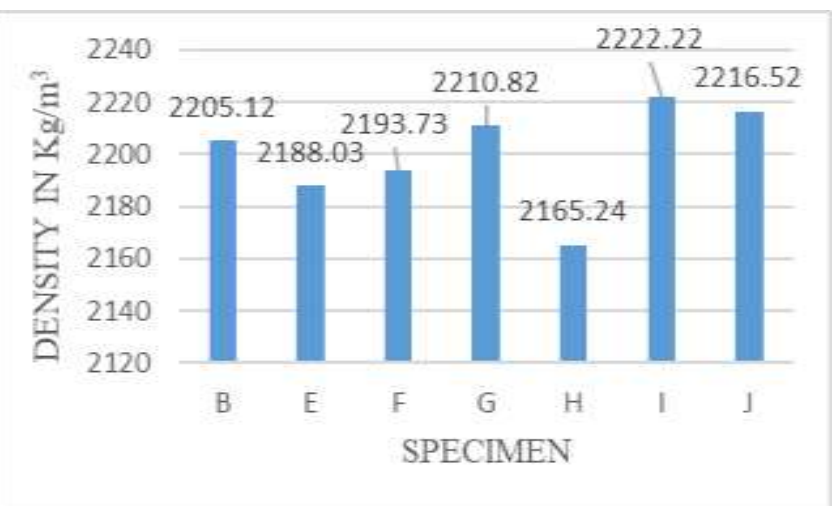

Fig 6: Density for specimen B, E, F, G, H, I and J 
It is observed that highest density is recorded for the control specimen $\mathrm{A}$, yet the specimen $\mathrm{B}$ having lower density compared to control it gave the best compressive strength, workability and flowability. From this it can be inferred that boron carbide has a considerable influence over the bondage of particles in mortar mix. It becomes clear that boron carbide in cement mortar is not just a filler material. The bulk density of specimen, upon addition of pozzolanic content, was found to be lesser than that of the control specimen. This may be due to the fact that microsilica and metakaolin due to their fineness and other material properties give a less dense specimen than A whereas the density of specimen E, F, $\mathrm{G}$ and $\mathrm{H}, \mathrm{I}, \mathrm{J}$ found to be individually increasing. This may be due to the fact that the weight of the hydration product formed after the pozzolaonic reaction is found to be increasing as the pozzolaonic content increases. The graphical representation of the above observation is shown in figure 6.

Though 15 micron size $\mathrm{B}_{4} \mathrm{C}$ may not react with many compounds in cement, it alters the physical properties of the mortar. There is a probability for the boron carbide to react with silica and form silicon boride and silicon carbide.

\subsection{Sorptivity Test}

If a mortar or concrete surface is exposed to wetting by water then the cumulative water absorption is proportional, during the initial absorption period, to the square root of elapsed wetting time' $t$ '. Both water absorption and capillary suction depend on porosity. Any non-uniformity in porosity could lead to different sorptivity values in the same sample. Hence all the materials under test must be homogenous and consistent. Sorptivity is calculated using the following formula

$$
\mathrm{S}=\frac{\mathrm{i}}{\sqrt{\mathrm{t}}}
$$

Where $\mathrm{S}$ is the sorptivity in metre per $\sqrt{\text { hour }}$ $i$ is the cumulative infiltration in metre

$t$ is the time period in hour

The weight of water absorbed and the corresponding sorptivity values of all specimens are graphically presented in figure 7,8 and 9.

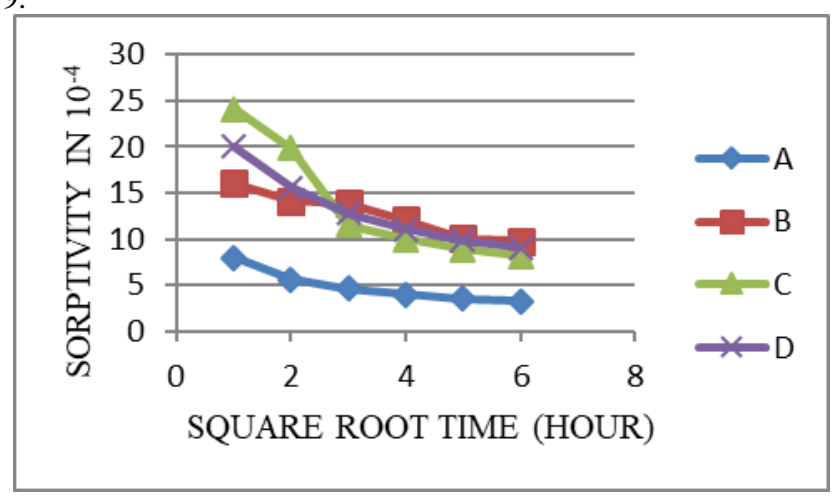

Fig 7: Sorptivity Vs time for specimen A, B, C, and D

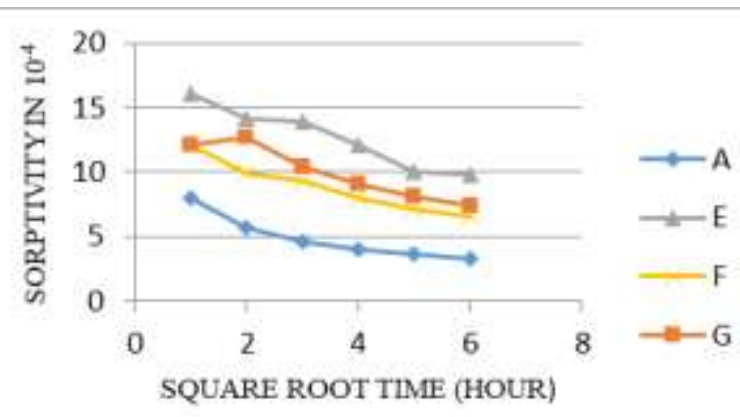

Fig 8: Sorptivity Vs time for specimen A, E, F, and G

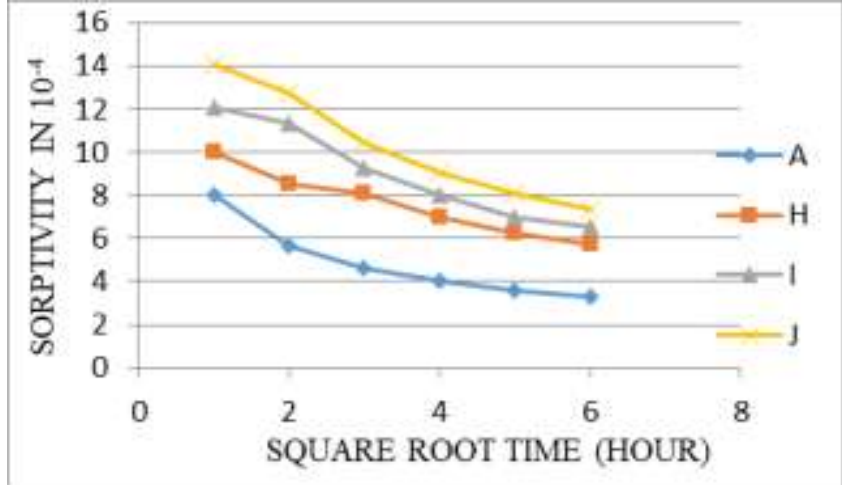

Fig 9: Sorptivity Vs time for specimen A, H, I, J

It can generally be seen that the control specimen or specimen A shows greater resistance to water absorption by capillary suction than specimen containing boron carbide and pozzolanic materials like microsilica and metakaolin.

From Fig 7 it is seen that due to addition of boron carbide the sorptivity values increases. From fig 8 and fig. 9 it is seen that, the sorptivity values decreases with increasing percentage of microsilica compared to control.

This observation is due to the fact that the capillary rise increases as the pore size decreases. Addition of metakaolin to the cement mortar mix reduces the void size by filling the void spaces present due to entrapped air.

\subsection{Alkalinity}

Alkalinity has a great influence on resistance to corrosion of steel in concrete and to the agents that induce corrosion, spallation and/or disintegration of concrete.
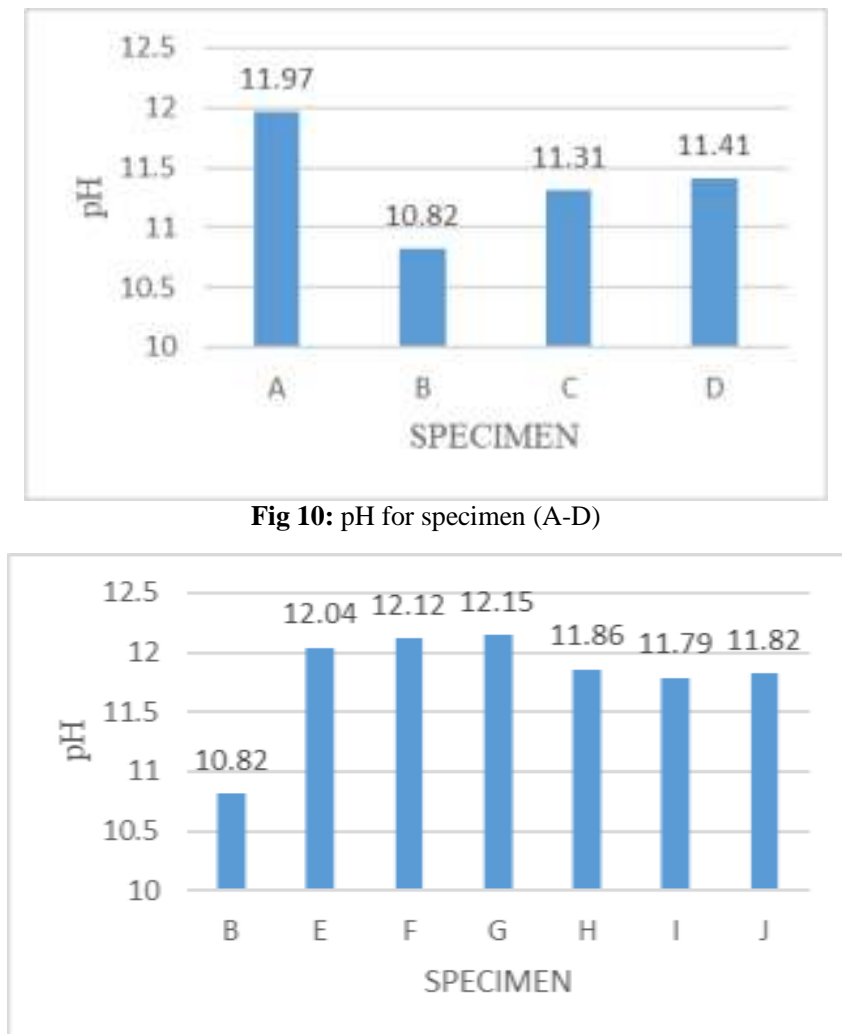

Fig 11: $\mathrm{pH}$ for specimen (B, E-J)

A reduction in $\mathrm{pH}$ is seen in specimen $\mathrm{B}, \mathrm{C}$ and $\mathrm{D}$ when compared to control specimen A. But specimen B gave high workability and compressive strength. It is inferred that due to addition of boron carbide a slight reduction is seen in $\mathrm{pH}$ of cement mortar, may be due to porous nature. 
With addition of pozzolanic materials in different proportions there was an improvement in $\mathrm{pH}$ when compared to specimen B. $\mathrm{B}$ has the least $\mathrm{pH}$ while specimen $\mathrm{G}$ has the highest. $\mathrm{H}$ is the specimen of interest as it had the highest compressive strength But the $\mathrm{pH}$ of $\mathrm{H}$ is slightly lesser than the specimen $\mathrm{G}$ which may be due to the porous nature of the specimen $\mathrm{H}$.

Since the specimens are mortar based which in practical will be used for only plastering purposes, will hardly come in contact with any reinforcement, hence the slight reduction in $\mathrm{pH}$ of the specimen $\mathrm{H}$ can be accepted as it also resembles to the $\mathrm{pH}$ value of the control specimen too.

\subsection{Absorption}

The cement paste consists of voids in the form of C-S-H gel pores and water filled or empty capillary cavities. The gel pores are extremely small and do not contribute to any permeability. Large capillary cavities which do not get filled by hydration products are the primary reason for permeability and hence water absorption in mortar.

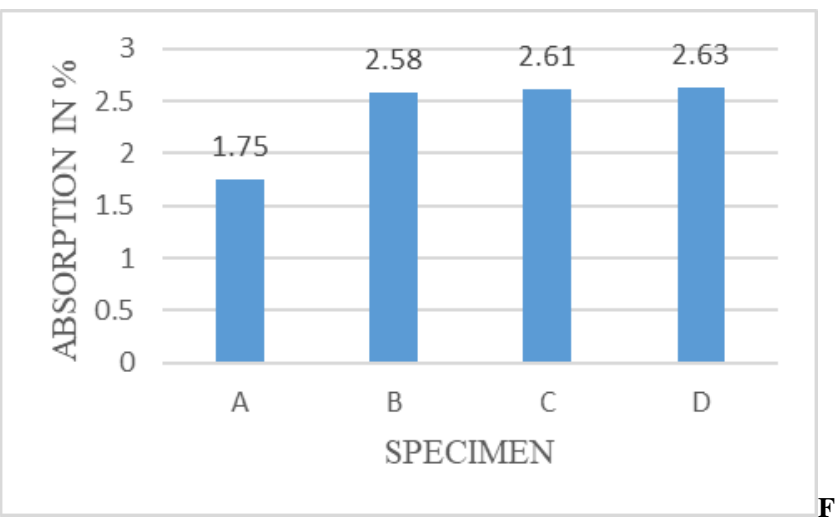

fig 12: Absorption values for specimen A, B, C and D

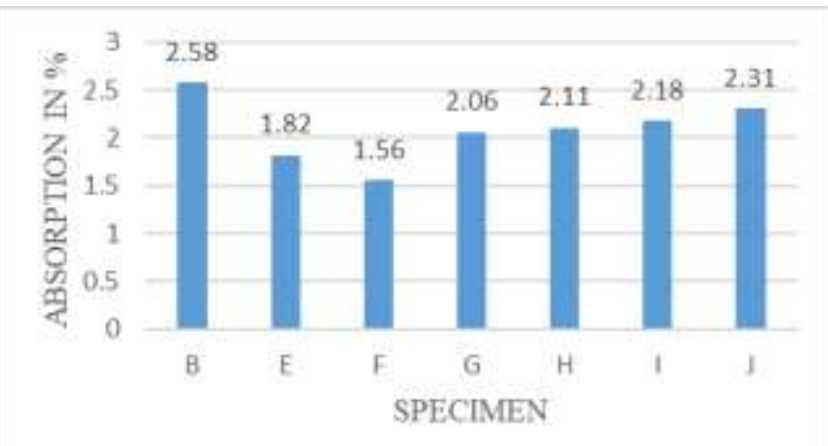

Fig 13: Absorption values for specimen B, E, F, G, H, I and J

An increase in absorption is seen due to addition of boron carbide. Control specimen A had a lesser absorption value when compared with specimen $\mathrm{B}, \mathrm{C}$ and $\mathrm{D}$. At this point it should be noted that the coefficient of permeability of cement paste is very low $\left(5 \times 10^{-11}\right.$ $\mathrm{m} / \mathrm{s}$ ) and is not directly responsible for the water absorption. The main reason behind water absorption is the development of micro cracks in the transition zone of the specimen that can be seen in FE-SEM study (Fig.14).

Specimen $\mathrm{H}$ has an absorption value lesser than specimen $\mathrm{B}$. This may be due to addition of pozzolanic materials that may fill up the pores and hence reduces the absorption percentage.

In the experiment carried out, the absorption capacity of specimen $\mathrm{H}$ closely resembles to that of control specimen A. The water absorption of specimen $\mathrm{H}$ is slightly higher than that of specimen $\mathrm{A}$. This may be due to the pozzolanic reaction between cement and metakaolin forming compounds that may alters the absorption value of the specimen as a whole.

\subsection{FE-SEM AND EDS Analysis}

SEM imaging and EDS mapping were done to understand the material characterisation of the specimen. Elemental compositions of all the specimens were obtained from EDS which was used to calculate the removal cross section value of the specimen.The EDS spectrum and scanning electron microscope study was carried out for all specimens to study the microstructure of the specimen and are represented in fig 14.
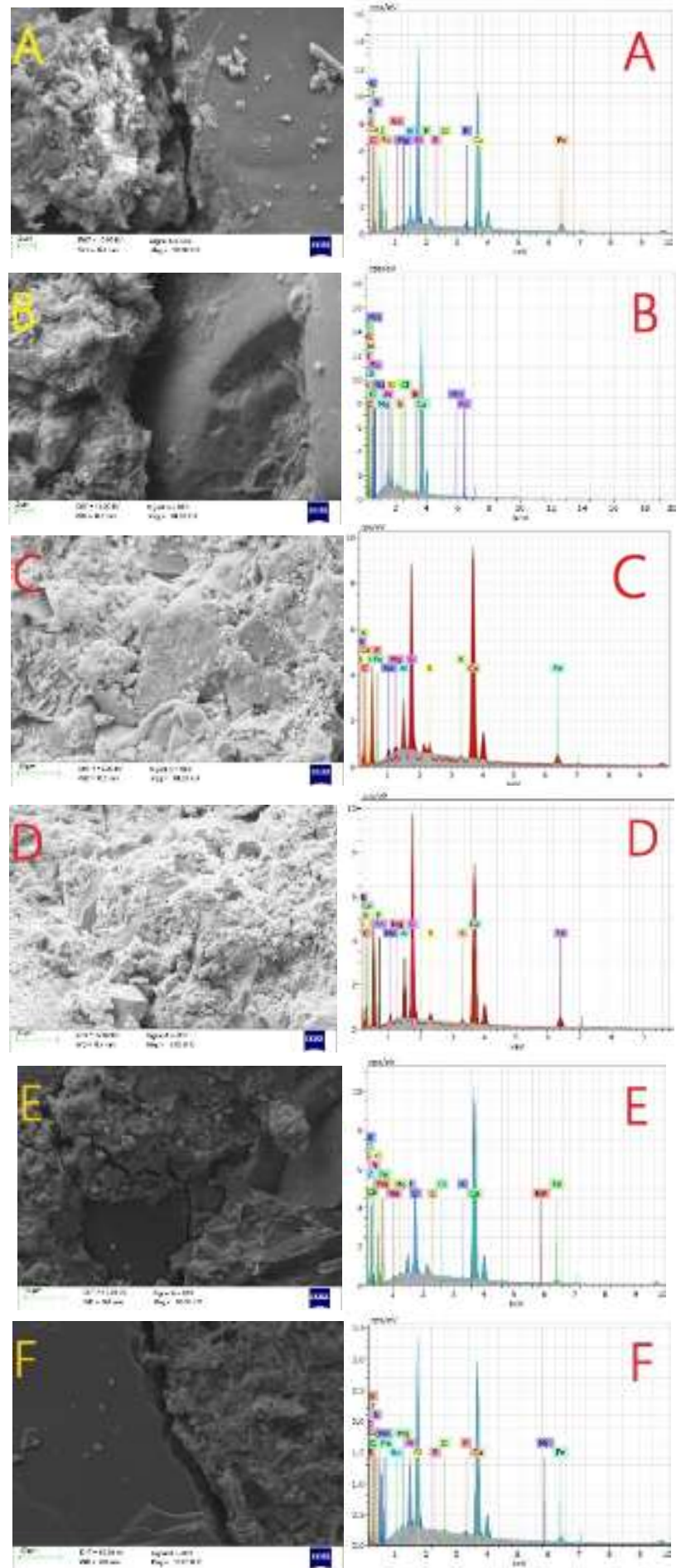

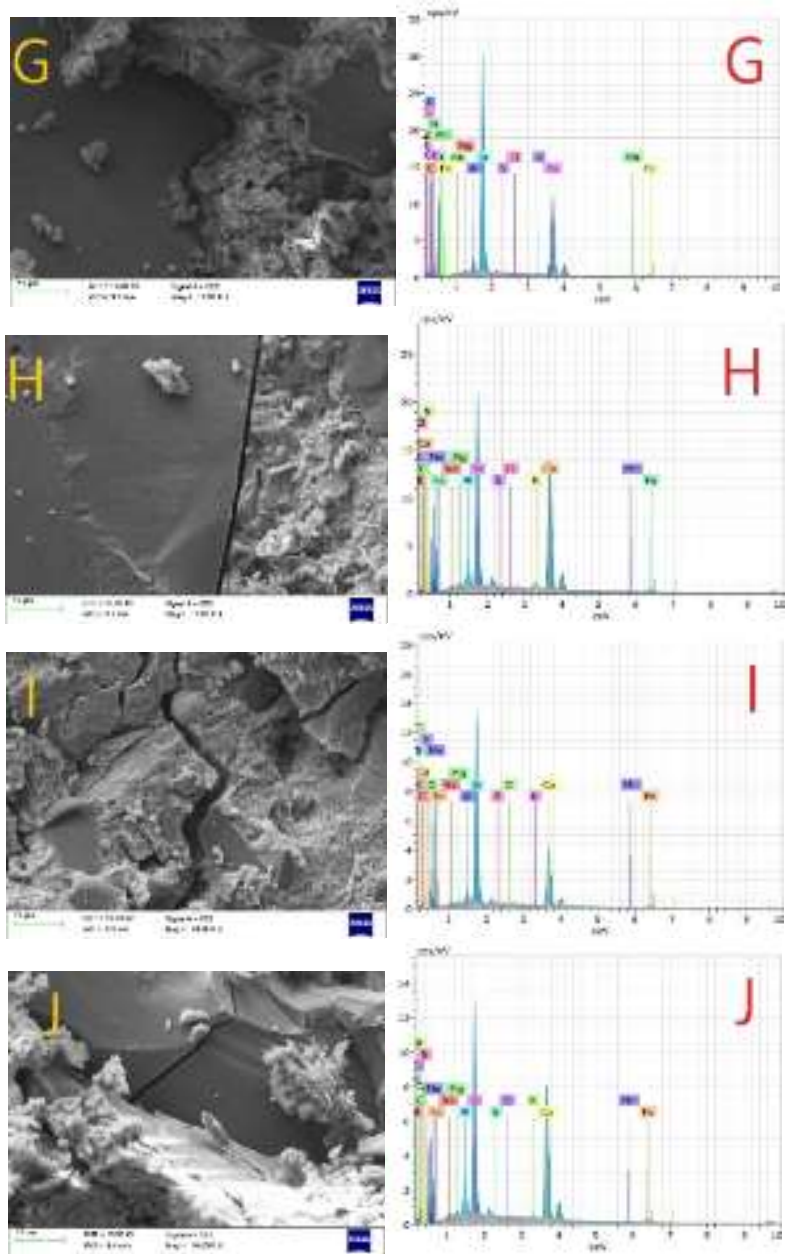

Fig 14: SEM and EDS for all specimens

In all the specimen (B-J) tested for FE-SEM analysis as shown in figure 14 , boron carbide crystals are clearly distinguishable from the surrounding hydration products and sand. Also the microstructure of the specimen shows the crack propagation and width of the gap between the $\mathrm{B}_{4} \mathrm{C}$ crystals and the cement matrix. Hence it can be safely inferred that boron carbide, in either proportion, does not participate in any reaction with cement and remains separate throughout the composition at normal temperature. This justifies the reason for the decreased strength due to addition of $\mathrm{B}_{4} \mathrm{C}$ alone in concrete.

\subsection{Removal Cross Section Analysis}

The macroscopic removal cross section value as a whole for a specimen is calculated by the programme ${ }^{[11]}$.To calculate this, the individual elemental composition is obtained by EDS analysis. The values obtained from this test is taken at a constant magnification for all specimen, and also the non-uniform distribution of 15 micron size boron carbide crystal and other components of the mix significantly varies the macroscopic removal cross section of the specimen in whole. Therefore macroscopic removal cross section calculation for all specimens with the EDS data gives an indication about the removal cross section of the test specimen.

The macroscopic cross-section represents the effective target area of all of the nuclei contained in the volume of the material. The calculation of removal cross section analysis can be carried out in cases where the specimen cannot be experimentally tested in the nuclear facility ${ }^{[11,19]}$. It is observed that there is a $10 \%$ deviation in the values when calculated using the empirical formula than with experimentally found out results. Consider a chemical compound $\mathrm{C}$ having, for instance, the chemical formula $\mathrm{X}_{\mathrm{i}} \mathrm{Y}_{\mathrm{j}} \mathrm{Z}_{\mathrm{k}}$, where $\mathrm{X}, \mathrm{Y}$ and $\mathrm{Z}$ are the chemical symbols of its elements and $\mathrm{i}, \mathrm{j}$ and $\mathrm{k}$ are their fixed proportions by mass, then the compound molar mass $\left(\mathrm{M}_{\mathrm{C}}\right)$ is given by:

$$
\mathrm{M}_{\mathrm{C}}=\mathrm{M}_{\mathrm{X}} \mathrm{i}+\mathrm{M}_{\mathrm{Y}} \mathrm{j}+\mathrm{M}_{\mathrm{Z}} \mathrm{k}(\mathrm{g} / \mathrm{mol})
$$

Where $M_{X}, M_{Y}$ and $M_{Z}$ are the atomic masses, of the elements $X$, $\mathrm{Y}$ and $\mathrm{Z}$ respectively. Hence the mass removal cross-section of the compound $\mathrm{C}$, in $\mathrm{cm}^{2} \mathrm{~g}^{-1}$, can be calculated by the following equation-

$$
\begin{aligned}
& \left(\sum_{\mathrm{R}} / \rho\right)_{\mathrm{C}}=\left\{\left(\mathrm{M}_{\mathrm{X}} \mathrm{i}\left(\sum_{\mathrm{R}} / \rho\right)_{\mathrm{X}}+\mathrm{M}_{\mathrm{Y}} \mathrm{j}\left(\sum_{\mathrm{R}} / \rho\right)_{\mathrm{Y}}+\mathrm{M}_{\mathrm{Z}} \mathrm{k}\left(\sum_{\mathrm{R}} / \rho\right)_{\mathrm{Z}}\right)\right\} / \mathrm{M}_{\mathrm{C}}(3) \\
& \left(\sum_{\mathrm{R}} / \rho\right)_{\mathrm{C}}=\mathrm{R}_{\mathrm{X}}\left(\sum_{\mathrm{R}} / \rho\right)_{\mathrm{X}}+\mathrm{R}_{\mathrm{Y}}\left(\sum_{\mathrm{R}} / \rho\right)_{\mathrm{Y}}+\mathrm{R}_{\mathrm{Z}}\left(\sum_{\mathrm{R}} / \rho\right)_{\mathrm{Z}}
\end{aligned}
$$

Where $R_{e}=M_{e} / M_{C}$ is the mass fraction of the element $e$ in the compound C. Generally, the mass removal cross-section of the compound $\mathrm{C}$ which contains $\mathrm{n}$ elements is found from

$\left(\sum_{\mathrm{R}} / \rho\right)_{\mathrm{C}}=\sum_{e=1}^{n} R_{e}\left(\frac{\sum_{R}}{\rho}\right)_{e}$

A macroscopic cross-section is derived from microscopic crosssection and the atomic number density. Figure 15 shows the removal cross section values calculated using the hand calculation method.

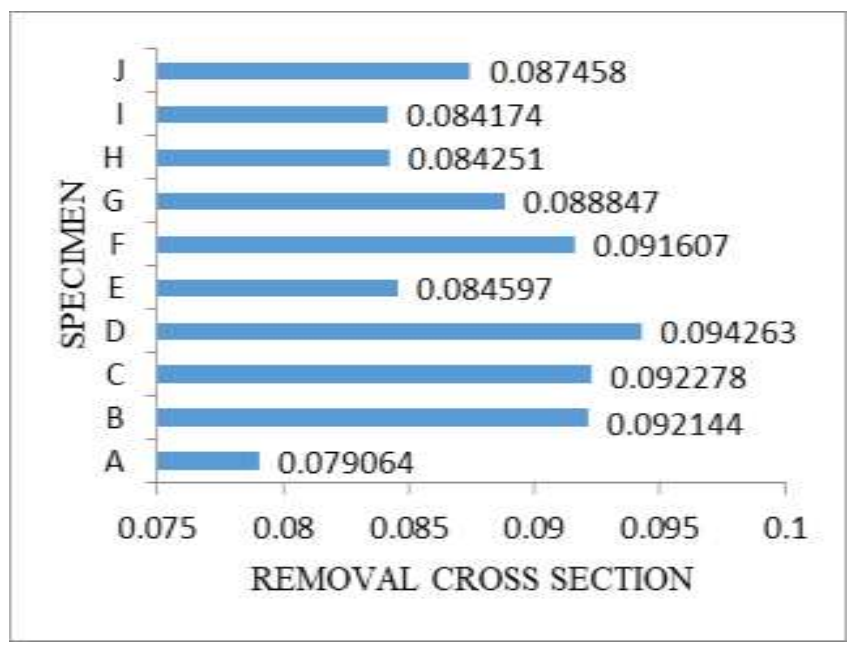

Fig 15: Removal cross section for all specimens

The removal cross section values for all specimens from A to $\mathrm{J}$ are shown in figure 15. The increase in the macroscopic removal cross section values from specimen $\mathrm{B}$ to D shows that boron carbide has neutron attenuating property and the neutron attenuation nature of a sample increases with increase in boron carbide content.

The decrease in the removal cross section values on addition of pozzolans in specimen $\mathrm{E}$ and $\mathrm{H}$ when compared with specimen $\mathrm{B}$ shows that the microscopic removal cross section of the components of the pozzolanic material like microsilica and metakaolin is actually lesser than the microscopic cross section values of the components present in the Portland pozzolana cement which is being replaced.

Considering all the performance and strength based parameters that ensure the suitability of the mortar for practical applications, the specimen $\mathrm{H}$ is suggested. Therefore to study the distribution of various elements present in specimen H, EDS mapping is done for all major elements present and are represented in figure 16. 


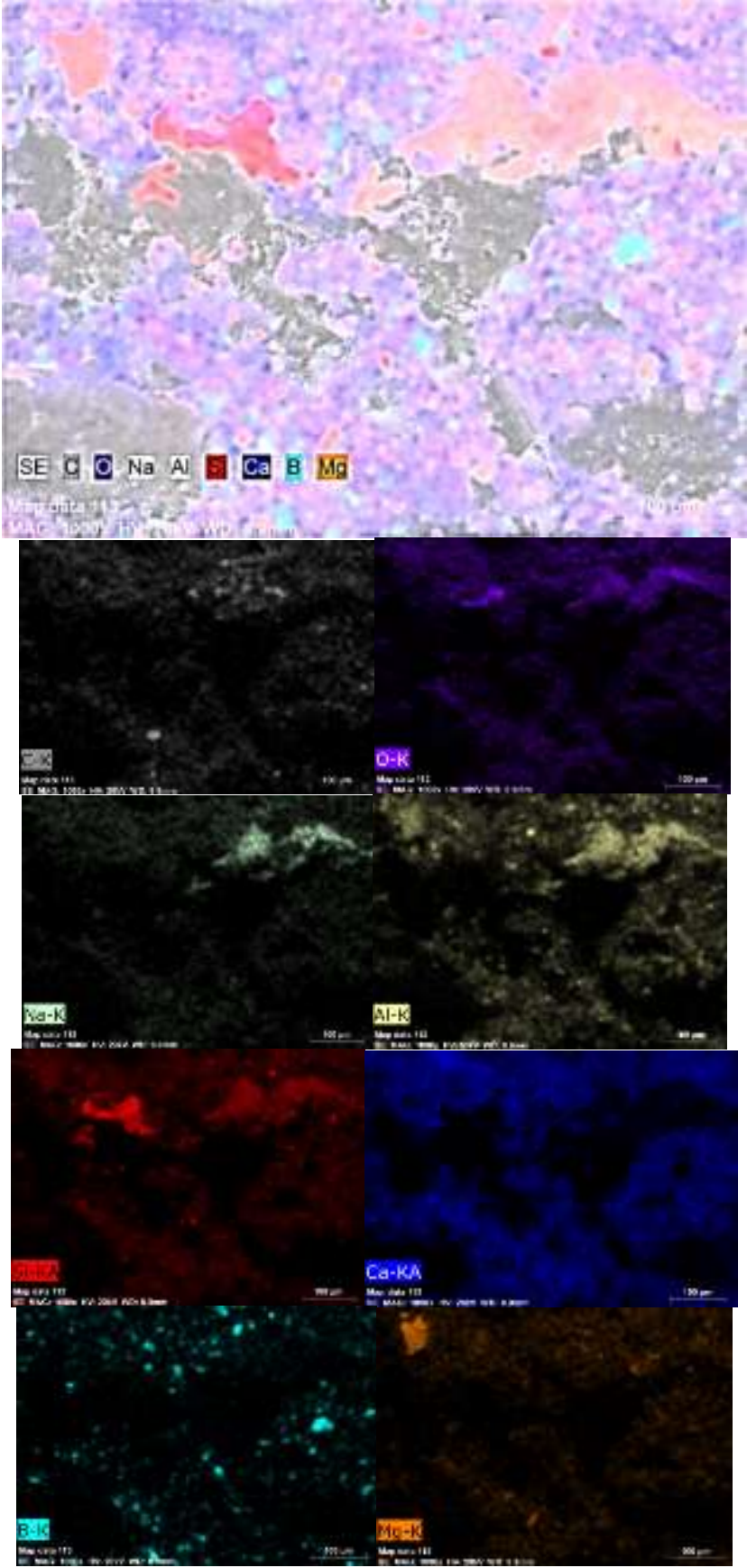

Fig 11: EDS mapping for specimen $H$

\section{Conclusion}

Neutron radiation is harmful to human kind. When there is neutron leakage in a place, water is stored around it so that it can stop the spread of the radiation to a great extent. Boron Carbide and Concrete have the capacity to attenuate neutrons. A cement mortar mixed with Boron Carbide and Glenium super-plasticizer can be lined in the nuclear plants for secondary shielding purpose. $1: 2$ (cement : sand) mortar mix is taken as the controlled specimen and $15 \%, 20 \%$ and $25 \%$ of cement weight of sand is replaced with Boron Carbide. Further, 1:2 mortar containing Boron Carbide of $15 \%$ cement weight is taken and $5 \%, 10 \%$ and $15 \%$ of cement is replaced with micro silica and metakaoline separately to improve the strength values. Three $70.6 \mathrm{~mm}$ size cubes were casted in each combination. Totally 30 cubes of size $70.6 \mathrm{~mm}$ containing various proportions of cement, sand, Boron Carbide, Micro silica and metakaoline were casted and tested for compression, workability, alkalinity, absorption and sorptivity. Microstructure of all the specimens were studied under SEM. Elemental composition of all the specimen were found using EDS and removal cross sectional values were calculated.

Hence it is observed that mere addition of boron carbide alone will proportionally increase the removal cross section value of the specimen as a whole as every other element present in the specimen possess neutron attenuating property to a certain degree. Therefore change in elemental composition of cement and water affects the total removal cross section value of the mortar mix. Secondly the size of the boron carbide and the way it gets distributed within the mortar mix will also affect the EDS spectrum distribution and hence the removal cross section value. Therefore the calculated values are approximate and are close to real. Results suggest that a mortar mix containing 15\% Boron Carbide and 5\% of metakaoline is found to have $26.54 \%$ more compressive strength, difference between flow percentage of this combination and the control specimen was found to be 30 , alkalinity and absorption values too were similar to the control specimen; so this mix is suggested for practical use.

\section{References}

[1] E. P. Blizard and J. M. Miller, 1958, Radiation Attenuation Characteristics of Structural Concrete, Oak Ridge National Laboratory, Contract No. W-7405-eng-26, ORNL-2193.

[2] Dubrovskii, V.B., Krasnoyarov, V., Kulakovskii, M. YA., Pergamenshchik, B.K., Pinkhasik, M.S., Savitskii, V.I., 1965. Uses of Concretes for high temperature shielding of nuclear reactors, Translated from Atomnaya nergiya, Vol. 19, NO.6, 524-529.

[3] Kaplan, M.F., 1989. Concrete Radiation Shielding. Longman Scientific \& Technical, England.

[4] Yarar Y, Bayülgen A, 1994. Investigation of neutron shielding efficiency and radioactivity of concrete shields containing colemanite. J. Nucl. Mater. (212-215): 1720-1723

[5] Desdin, L., Ceballos, C., 2000. Neutron reflection method for the fast estimation of neutron removal cross section in hydrogenous materials. J. Radioanal. Nucl. Chem. 243 (3), 835-837

[6] Briesmeister, J.F., 2000. MCNP_A general Monte Carlo n-particle transport code, version 4C, LA-13079-M, Los Alamos, USA.

[7] C.Subramanian, A.K.Suri., Development of boron based neutron absorber materials, Met. Mater.Process., 2004, 16, (1), 39-52.

[8] Facure, A., Silva, A.X., 2007 The use of high-density concretes in radiotherapy treatment room design, Applied Radiation and Isotopes $65,1023-1028$

[9] Kharita, M.H., Yousef, S., Alnassar, M., 2008. Heat effect on the shielding and strength properties of some local concretes. Progress in Nuclear Energy 50, 22 - 26

[10] Kharita, M.H., Takeyeddin, M., Alnassar, M., Yousef, S., 2008. Development of special radiation shielding concretes using natural local materials and evaluation of their shielding characteristics. Progress in Nuclear Energy 50, 33-36

[11] A.M. El-Khayatt, A. El-Sayed Abdo., 2009 A program for the calculation of fast neutron removal cross sections in composite shields, Annals of Nuclear Energy 36 (2009) 832-836

[12] El-Khayatt A.M., 2010, Calculation of fast neutron removal crosssection for some compounds and materials, Annals of Nuclear Energy 37 218-222

[13] C.Subramanian, A.K.Suri and T.S.R.Ch.Murthy, 2010, Development of Boron-based materials for nuclear applications, BARC Newsletter, Issue No 313 • Mar. - Apr. 2010.

[14] Vladislav Domnich., Sara Reynaud., Richard A. Haber., Manish Chhowalla., 2011. Boron Carbide: Structure, Properties, and Stability under Stress,3605-3628

[15] Yusof Abdullah, Mohd Reusmaazran Yusof, Rusnah Mustaffa, Abdul Aziz Mohamed, Fatin Nabilah Tajul Ariffin and Nurhaslinda Ee Abdullah, 2011., Properties Of Concrete/Boron Carbide As Neutron Shielding Materials, Journal Of Nuclear And Related Technologies, Volume 8, No. 2, December, 2011.

[16] Kharita, M.H., Yousef, S., Alnassar, M., 2011. Review on the addition of boron compounds to radiation shielding concrete. Progress in Nuclear Energy 53, 207-211

[17] Fatin Nabilah, Tajul Ariffin, Yusof Abdullah, Roslinda Shamsudin, Roszilah Hamid and Sahrim Haji Ahmad, 2011, Effect of Boron Carbide Addition on the Physical, Mechanical and Microstructural Properties of Portland Cement Concrete, Journal of Applied Sci- 
ences 11 (22): 3738-3743, 2011; ISSN 1812-5654 / DOI: 10.3923/jas.2011.3738.3743

[18] Z. Q. Shen, Q. Kang, J. Xu, Z. G. Wang, Y. J. Zeng 2012, "Attenuation Ratios of Cement-Based Materials Containing B4C to 14.8MeV Neutron", Applied Mechanics and Materials, Vols. 193194, 402-405

[19] Y. Elmahrough, B.Tellili and C.Souga., 2013 Calculation Of Fast Neutron Removal Cross-Sections For Different Shielding Materials, International Journal of Physics and Research, ISSN 22500030, Vol. 3,Issue 2, Jun 2013,7-16.

[20] Salim Orak, Derya Yilmaz Baysoy, 2013, Neutron Shielding Properties Of Concrete With Boron And Boron Containing Mineral, Academic Platform Journal of Engineering and Science I-I (2013) 1519.

[21] Sariyer, D., Küçer, R., Küçer, N., 2015. Neutron Shielding Properties of Concretes Containing Boron Carbide and Ferro - Boron Procedia - Social and Behavioral Sciences 195, 1752 - 1756. 